\title{
Laser Fusion of Aluminum Powder Coated with Diamond Particles via Selective Laser Melting: Powder Preparation and Synthesis Description
}

\author{
Alexander S. Shinkaryov ${ }^{1}{ }^{(D)}$, Dmitriy Yu Ozherelkov ${ }^{1}{ }^{(D)}$, Ivan A. Pelevin ${ }^{1}{ }^{(D)}$, Sergey A. Eremin ${ }^{1}$,

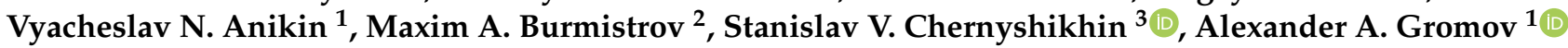 \\ and Anton Yu Nalivaiko $1, * \mathbb{D}$
}

1 MISIS Catalysis Laboratory, National University of Science and Technology MISIS, 119991 Moscow, Russia; shinkaryov@gmail.com (A.S.S.); d.ozherelkov@gmail.com (D.Y.O.); i.pelevin@misis.ru (I.A.P.); serega21_93@mail.ru (S.A.E.); anikin47_47@mail.ru (V.N.A.); a.gromov@misis.ru (A.A.G.)

2 Technical Directorate, AddSol Manufacturing Company, 115201 Moscow, Russia; $9851144578 @ m a i l . r u$

3 Center for Design, Manufacturing and Materials, Skolkovo Institute of Science and Technology, 121205 Moscow, Russia; stanislav.chernyshikhin@skoltech.ru

* Correspondence: nalivaiko@misis.ru; Tel.: +7-(495)-955-0137

Citation: Shinkaryov, A.S.; Ozherelkov, D.Y.; Pelevin, I.A.; Eremin, S.A.; Anikin, V.N.; Burmistrov, M.A.; Chernyshikhin S.V.; Gromov, A.A.; Nalivaiko, A.Y. Laser Fusion of Aluminum Powder Coated with Diamond Particles via Selective Laser Melting: Powder Preparation and Synthesis Description. Coatings 2021, 11, 1219 https://doi.org/10.3390/ coatings11101219

Academic Editor: Alessio Lamperti

Received: 1 September 2021

Accepted: 3 October 2021

Published: 5 October 2021

Publisher's Note: MDPI stays neutral with regard to jurisdictional claims in published maps and institutional affiliations.

Copyright: (c) 2021 by the authors. Licensee MDPI, Basel, Switzerland. This article is an open access article distributed under the terms and conditions of the Creative Commons Attribution (CC BY) license (https:// creativecommons.org/licenses/by/ $4.0 /)$.
Abstract: This work aims to study the possibility of obtaining Al-C composite from AlSi10MgCu aluminum matrix with the addition of $500 \mathrm{~nm}$-sized diamond particles by selective laser melting (SLM) process. Al-C composite powder was prepared by mechanical mixing to form a uniform cover along the surface of aluminum particles. The diamond content in the resulting AlSi10MgCu-diamond composite powder was equal to $0.67 \mathrm{wt} \%$. The selection of the optimal SLM parameters for the obtained composite material is presented. For materials characterization, the following methods were used: scanning electron microscopy (SEM), transmission electron microscopy (TEM), X-ray diffraction (XRD), and Raman spectroscopy. X-ray photoelectron spectroscopy (XPS) was applied after SLM printing for a detailed investigation of the obtained composites. The presence of carbon additives and the formation of aluminum carbides in the material after the SLM process were demonstrated.

Keywords: laser fusion; aluminum powder; nanodiamond; additive manufacturing; selective laser melting; coated powder; metal matrix composites

\section{Introduction}

Composite materials are widely used in many fields of structural applications due to their excellent properties, which significantly exceed the characteristics of traditional materials. Aluminum and aluminum-matrix composites (AMC) have high corrosion resistance and a successful combination of high strength with low density, which gives good specific strength [1-3]. AMC and other metal matrix composites (MMC) are widely used for various applications in the aerospace and automotive industries due to their excellent properties, such as light weight, high specific strength, and good wear resistance. The production of details and components for the needs of such high-technology industries is always a challenge. Selective laser melting (SLM) gives an excellent opportunity for creating new MMC with superfine microstructures, optimized weight, high strength, and stiffness [4-13]. Introducing new dissimilar components such as reinforcing particles or fibers into the matrix material $[14,15]$ allows us to receive a new material with properties quantitatively and qualitatively different from the original ones.

Currently, the application of different carbon allotropes in the MMC was studied [16,17]. Among these allotropes, the metal matrix diamond composite has the highest strength and is widely used to manufacture various diamond cutting and drilling tools. It is challenging to form diamond abrasive tools with complex structures by traditional powder metallurgy technology. The holding force of metallic matrix to diamond cannot achieve a high level, 
and the diamond abrasive was easily lost during the grinding process [18]. In this regard, additive manufacturing technologies such as SLM offer a high potential to fabricate metal bonded diamond tools with complex structures.

Diamond particles with different sizes are considered as perspective reinforcements for AMC. Diamond is one of the carbon allotropes [19] with a high hardness of about $100 \mathrm{GPa}$ and very high thermal conductivity up to $2200 \mathrm{~W} /(\mathrm{m} \mathrm{K})$. Diamonds are characterized by high Young's modulus, electrical resistivity, and good chemical stability; such properties make this material interesting for usage as an additive for metal matrix composites. In paper [20], a diamond composite was obtained by plasma sintering, and diamond particles were covered with a Ti layer to increase adhesion and make an interface between Al-matrix and diamond additives.

Some recent publications were devoted to selective laser melting of metal-diamond composites, in which diamond particles with a size of several tens $(25-45 \mu \mathrm{m})$ of micrometers are used as additives to metal matrix material [21,22]. For instance, Spierings et al. [22] describe the possibility of obtaining metal-matrix composites with diamond additives by the SLM method for creating metalworking tools. The study from Constantin et al. [23] is devoted to thermal interface development for more efficient cooling of electronic devices. The samples obtained during experiments described in the report [21] by Ma et al. had high porosity and relatively low hardness; it was not possible to achieve a relative density above $90 \%$. From the above mentioned reports [21-23], obtaining a high relative density of a metal-diamond composite is quite challenging. An example is reported in [22], where the authors achieved high material density above $95 \%$, but at the expense of the composite material tending to crack along the build direction.

To the best of our knowledge, the description of composites with submicron and nanodiamond additives and particles less than $1 \mu \mathrm{m}$ in size obtained by selective laser melting has not been reported so far. Submicron and nanosized diamond particles are more active than micron-sized additives. Lower energy density should be used to maintain their initial state in the resulting composite material after laser treatment. On the contrary, sufficient melting of aluminum particles occurs at higher energy densities. At such complicated process conditions, resulting high temperature leads to the graphitization of diamond particles [22], hence additive particles could be modified during the process. Additionally, there is a possibility of reaction progress between the graphitized diamond particles and the inclusion of water in composite material leading to gas formation during the printing process. Such phenomena can adversely affect the density of the material obtained by the SLM.

Studying the possibilities of obtaining aluminum matrix composites with fine diamond additives with a size of less than $1 \mu \mathrm{m}$ is an urgent task from the point of view of improving aluminum materials' physical and mechanical properties. In this work, aluminumdiamond composites (with diamond content $0.67 \mathrm{wt} \%$ ) were produced. AlSi $10 \mathrm{MgCu}$ powder was coated by fine diamond particles with an average size of $500 \mathrm{~nm}$. Aluminum powder and diamond particles additive were mixed in a laboratory roller mill. The usage of mechanical mixing is a typical way for obtaining composite powders [24,25]. This paper aimed to study the processibility of aluminum-diamond composite powder coated with $500 \mathrm{~nm}$ diamond particles during the selective laser melting process.

\section{Materials and Methods}

The initial aluminum powder used for composite preparation was made from $\mathrm{AlSi} 10 \mathrm{MgCu}$ alloy. Aluminum powder particles had a median diameter of $D_{50}=43 \mu \mathrm{m}$. This powder was obtained by a gas spraying of molten metal. Aluminum powder's chemical composition was analyzed by Oxford Aztec equipment using the energy-dispersive X-ray spectroscopy (EDX method). Matrix material used for composite preparation was AlSi10MgCu; matrix had the following chemical composition, wt $\%: 87 \% \mathrm{Al}, 10.7 \% \mathrm{Si}, 0.5 \% \mathrm{Mg}, 0.7 \% \mathrm{Cu}, 0.5 \%$ $\mathrm{Mn}, 0.2 \% \mathrm{Ti}, 0.3 \% \mathrm{Fe}$ and less than $0.1 \%$ of other impurities. 
Nanodiamonds were synthesized by detonating an explosive mixture with a TNT/RDX ratio of 1.5. The synthesis was carried out by a detonation from a condensed explosive composition with a negative oxygen balance. The detonation of charges resulted in the decomposition with the "free carbon" release in a cooling medium. Nanodiamond powder after synthesis (blend) contained about $40 \mathrm{wt} \%$ of non-diamond carbon and $60 \mathrm{wt} \%$ of the diamond. Non-diamond carbon was removed by a two-stage washing: (i) washing with a mixture of nitric and sulfuric acids in the first stage; (ii) washing with distilled water in the second stage. Then, the nanodiamond powder was thoroughly dried. [26].

Diamond particles were studied using a transmission electron microscope (TEM) JEOL JEM 2100 (JEOL, Tokyo, Japan) to analyze the shape and size of particles. For TEM analysis, a suspension of powder and water was applied to a copper mesh and then dried. The phase composition of the initial diamond was studied by X-ray diffraction (XRD) analysis on Difrey-401 diffractometer (Scientific instruments, Saint Petersburg, Russia), aluminum powder particles covered with diamond were analyzed with Thermo DXR Raman Imaging Microscope using the Raman light scattering method. AlSi10MgCu powder was coated by fine diamond particles with $500 \mathrm{~nm}$ size, mechanical seeding of matrix material with diamond additive was carried out on a laboratory roller mill. The mixing procedure ensured the complete covering of the initial matrix powder. That is why the aluminum powder was mixed with covering diamond particles at drum rotation speed $\omega=48 \mathrm{rpm}$ that ensured the absence of grinding. A total of $4 \mathrm{~g}$ of diamond particles were added to $600 \mathrm{~g}$ of initial aluminum powder to cover the aluminum matrix particles with several diamond monolayers during the mixing process. Thus, the diamond content in AlSi10MgCu-diamond composite powder was equal to $0.67 \mathrm{wt} \%$.

An SLM Solutions 280 HL 3D printer (SLM Solutions, Lübeck, Germany) was equipped with fiber laser for the experimental SLM printing process. All samples were synthesized in an argon atmosphere. The residual oxygen content in the working area was less than 0.2 vol.\%. The selection of optimal printing modes for AlSi10MgCu powder coated with diamonds was carried out on samples with $10 \times 10 \mathrm{~mm}$ size samples with a thickness of $300 \mu \mathrm{m}$. The size of the laser spot during printing was $80 \mu \mathrm{m}$, the thickness of the powder layer during printing was $50 \mu \mathrm{m}$. Hatch distance was fixed for all modes and equal to $130 \mu \mathrm{m}$. Samples were built in the Z-axis direction, and a scanning strategy with 67 degrees rotation from layer to the layer was used. The substrate material used during the experimental printing was an aluminum-magnesium alloy of the AlMg5 grade (chemical composition: $94 \% \mathrm{Al}, 5 \% \mathrm{Mg}, 0.5 \% \mathrm{Mn}, 0.2 \% \mathrm{Si}$ and no more than $0.1 \%$ of other impurities). Printing parameters varied in the following ranges: laser power $P=250-370 \mathrm{~W}$, and scanning speed $V=850-1650 \mathrm{~mm} / \mathrm{s}$. Printing modes for the experimental SLM process and the results of printed samples' hardness determination are presented in Table 1. Laser energy density $Q\left(\mathrm{LED}, \mathrm{J} / \mathrm{mm}^{2}\right.$ ) for different printing modes listed in Table 1 was calculated according to the following formula (1):

$$
Q=\frac{P}{V \cdot h},
$$

where $P$-power of laser radiation source, $\mathrm{W} ; \mathrm{V}$-scanning speed of the laser beam, $\mathrm{mm} / \mathrm{s}$; $h$-hatch distance spacing, $\mathrm{mm}$.

Table 1. Printing modes of AlSi10MgCu-diamond powder.

\begin{tabular}{ccccc}
\hline $\begin{array}{c}\text { Sample } \\
\text { Code }\end{array}$ & Laser Power, W & Scanning Speed, $\mathbf{m m} / \mathbf{s}$ & Hatch Distance, $\mathbf{~ m m}$ & LED, J/mm $\mathbf{m}^{\mathbf{2}}$ \\
\hline 1 & 370 & 850 & 0.13 & 3.35 \\
\hline 2 & 370 & 1050 & 0.13 & 2.71 \\
\hline 3 & 370 & 1250 & 0.13 & 2.28 \\
\hline 4 & 370 & 1450 & 0.13 & 1.96 \\
\hline
\end{tabular}


Table 1. Cont.

\begin{tabular}{ccccc}
\hline $\begin{array}{c}\text { Sample } \\
\text { Code }\end{array}$ & Laser Power, W & Scanning Speed, $\mathbf{m m} / \mathbf{s}$ & Hatch Distance, $\mathbf{m m}$ & LED, J/mm $\mathbf{m}^{2}$ \\
\hline 5 & 370 & 1650 & 0.13 & 1.72 \\
\hline 6 & 300 & 850 & 0.13 & 2.71 \\
\hline 7 & 300 & 1050 & 0.13 & 2.20 \\
\hline 8 & 300 & 1250 & 0.13 & 1.85 \\
\hline 9 & 300 & 1450 & 0.13 & 1.59 \\
\hline 10 & 300 & 1650 & 0.13 & 1.40 \\
\hline 11 & 250 & 850 & 0.13 & 2.26 \\
\hline 12 & 250 & 1050 & 0.13 & 1.83 \\
\hline 13 & 250 & 1250 & 0.13 & 1.54 \\
\hline 14 & 250 & 1450 & 0.13 & 1.33 \\
\hline 15 & 250 & 1650 & 0.13 & 1.17 \\
\hline
\end{tabular}

Printed samples were investigated using X-ray photoelectron spectrometer PHI 5000 VersaProbe II (Physical Electronics Inc., Chanhassen, MN, USA) . The elemental composition was studied at $50 \mathrm{~W}$ power with a $200 \mu \mathrm{m}$ diameter of the analysis area. Atomic concentrations were determined from survey spectra by the relative sensitivity factors of elements. The binding energies of the photoelectron lines were determined from the high-resolution spectra of Al2p, Si2p, and C1s recorded at an analyzer transmission energy of $23.5 \mathrm{eV}$. The error in determining the intensities of the peaks was $\pm 5 \%$. Ion etching was carried out to study the composition at different depths under the surface of printed samples; the surface layer was removed by $\mathrm{Ar}+$ ions with an energy of $2 \mathrm{keV}$. XRD analysis of printed composite was carried out using the same equipment as the initial diamond powder. Scanning electron microscopy (SEM) of Al-C samples was carried out on a Tescan Vega 3 (Tescan, Fuveau, France) microscope with an Oxford Instruments energy-dispersive X-ray spectroscopy (EDX) attachment. Sample preparation for SEM analysis consisted of a grinding-polishing procedure of printed samples using $\mathrm{SiO}_{2}$ polishing spray. The hardness of obtained Al-C composites was tested by the Vickers method, and the loading test force used was $490.3 \mathrm{~N}$.

\section{Results and Discussion}

The powder was examined by SEM analysis. These initial matrix powder particles have a predominantly rounded shape (Figure 1). The surface of the powder is smooth, with some satellites on the surface. Gas-dynamic conditions often cause the formation of such satellites during the spraying of the melt in powder production.
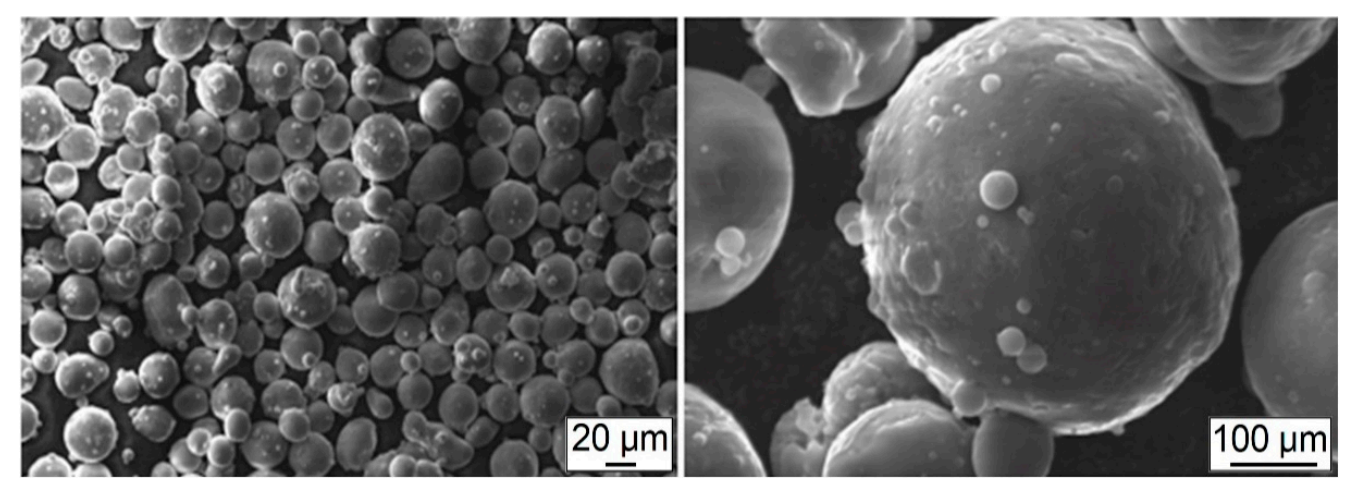

Figure 1. SEM images of the AlSi10MgCu powder. 
Images obtained by TEM are shown in Figure 2. Diamond particles used in this study have a thin debris shape with sharp edges and a thickness of $20-30 \mathrm{~nm}$. The average size of diamond particles used in this study was about $500 \mathrm{~nm}$. Lamellar diamond powder particles with such a plate-shape could be considered as nanodiamond particles because of their low thickness in one dimension. This form of particles allows the diamond to adhere to the AlSi10MgCu powder particles mechanically firmly after mixing.
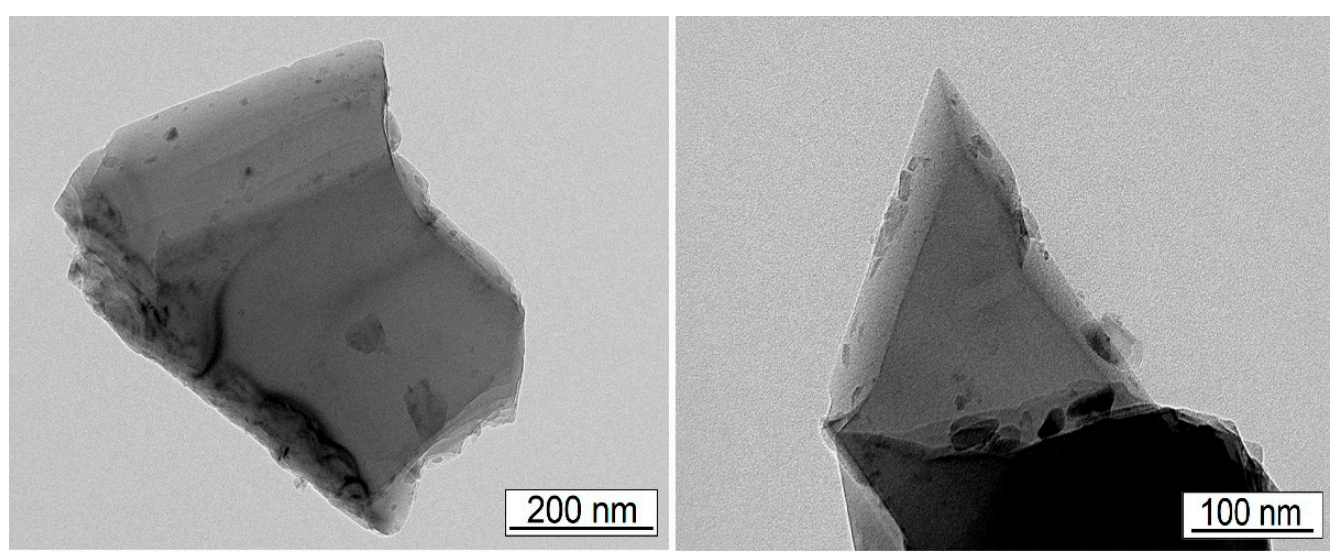

Figure 2. TEM images of the diamond powder with $500 \mathrm{~nm}$ fraction.

The XRD diffraction pattern of initial diamond particles is shown in Figure 3. Two distinct peaks characterize the diamond phase; there were no metal impurities detected.

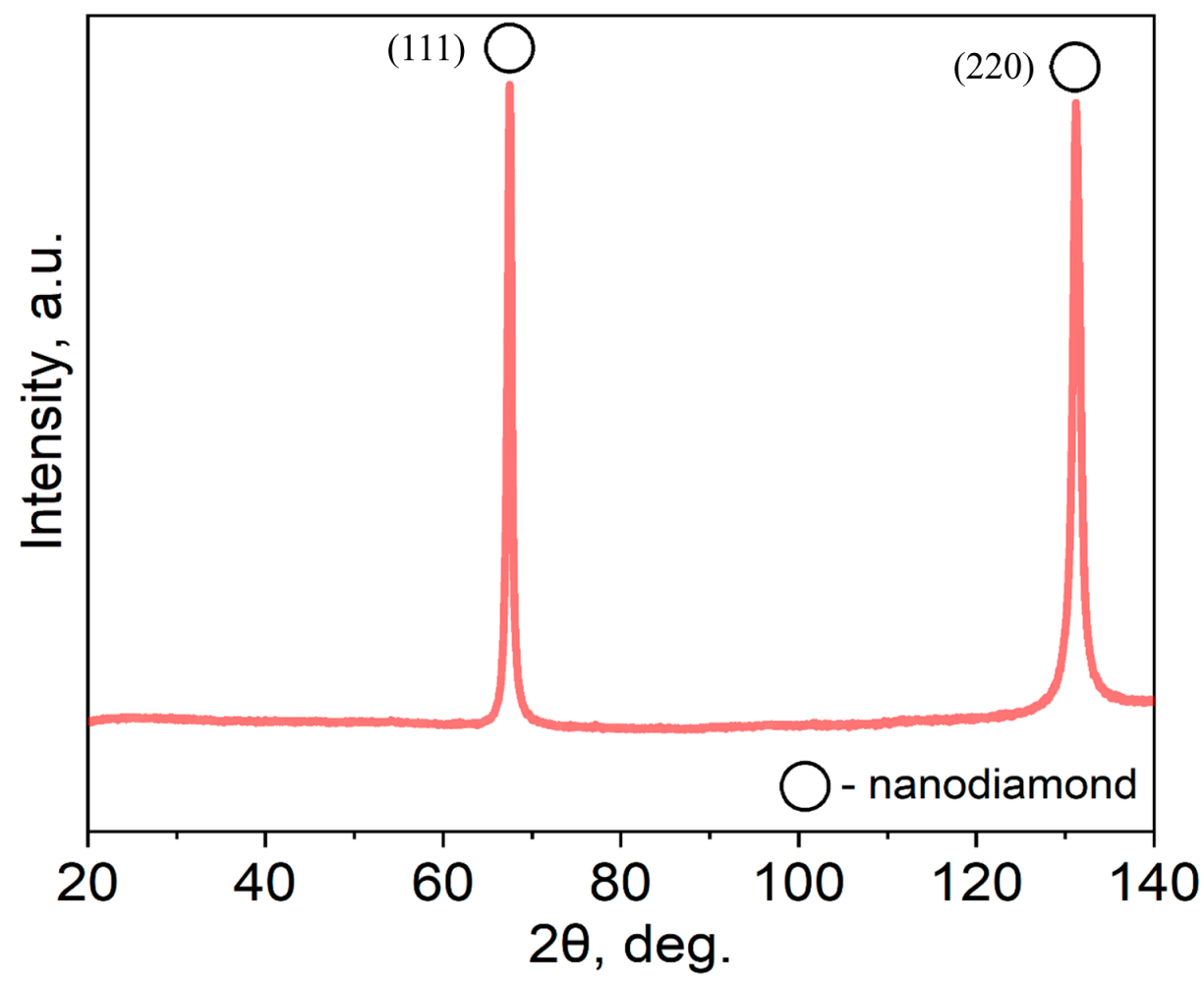

Figure 3. XRD pattern of initial nanodiamond particles.

The SEM images provided in Figure 4 show aluminum powder particles coated with a diamond fraction of $500 \mathrm{~nm}$ in a roller mill. It could be seen that powder particles were covered with several monolayers of diamond particles. Since the concentration of the covering diamond particles is less than $1 \mathrm{wt} \%$, the spectra were recorded by Thermo DXR 
Raman Imaging Microscope using Raman light scattering, and the results are shown in Figure 5.
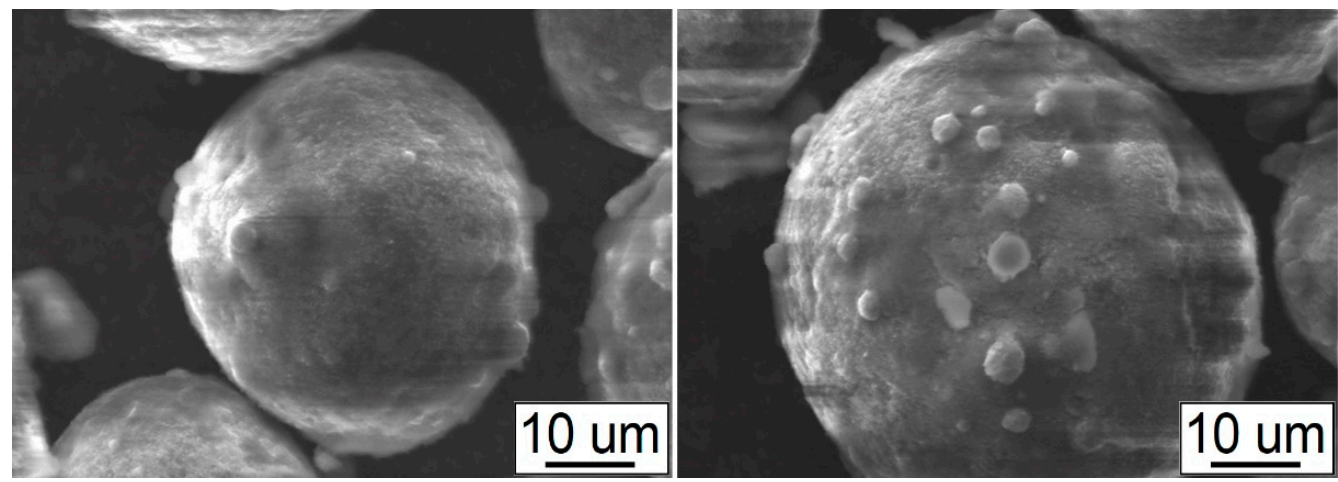

Figure 4. SEM images of the AlSi10MgCu powder particles coated with nanodiamond.
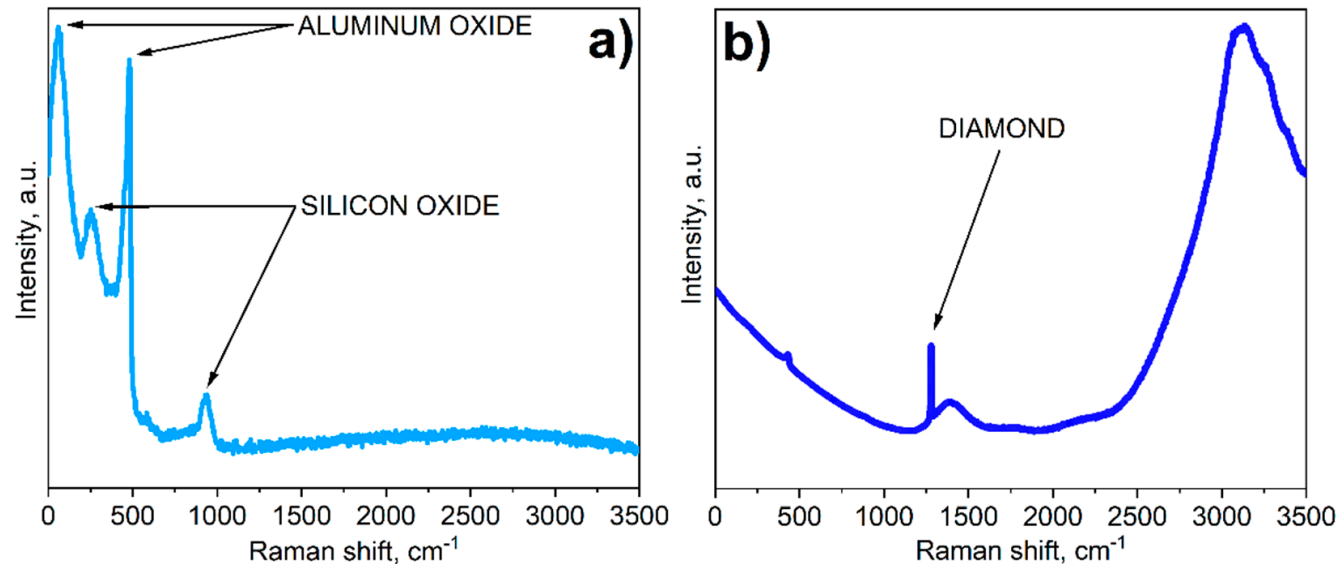

Figure 5. Raman spectra of AlSi10MgCu powder coated with diamond particles: (a) spectrum of the initial powder; (b) powder coated with diamond fraction $500 \mathrm{~nm}$.

The spectrum of the initial powder recorded by Raman spectroscopy is shown in Figure $5 \mathrm{a}$, where peaks corresponding to aluminum and silicon oxides can be indicated. The spectrum of the obtained composite powder is shown in Figure $5 \mathrm{~b}$. There is a characteristic peak of a diamond at $1333 \mathrm{~cm}^{-1}$. This peak at the Raman shift indicates the presence of diamond particles in composite powder. The shift specified at the spectrum plot indicates the presence of diamond particles on the surface of aluminum powder material. The Raman shift indicates the energy difference between the incident light and the scattered light. During the Raman spectroscopy analysis, the interaction occurs between electromagnetic radiation and diamond covering layers on the surface of particles. The absence of other peaks on the plot shows that the diamond plate layers thoroughly coat aluminum powder particles, and underlying aluminum material could not be detected.

The survey spectrum of the original printed Al-C sample surface is shown in Figure 6. The results are presented only for one composite sample as representative for all obtained samples. The presence of carbon in this sample was confirmed by the appearance of $\mathrm{C} 1 \mathrm{~s}$ peak at $285.0 \mathrm{eV}$. Such a peak is typical for adsorbed carbon, which could be absorbed by the sample surface from the gas media during the SLM printing process. CO gas could be formed during the reaction between graphitized nanodiamonds and water. As may be seen from Table 2, some samples were destroyed after printing. We assume that these samples had low mechanical properties due to residual oxygen and inappropriate printing modes. Additionally, one of the possible reasons which caused the non-sufficient performance of Al-C samples after SLM, was the reaction between graphitized nanodiamond and absorbed 
water: $\mathrm{C}+\mathrm{H}_{2} \mathrm{O} \rightarrow \mathrm{CO}+\mathrm{H}_{2}$ [27]. Other printed samples demonstrated better properties, and the best hardness results were obtained after SLM with high power and high scanning speed modes. A peak in the 104-105 eV region in Figure 6 shows the presence of silicon oxide on the initial surface.

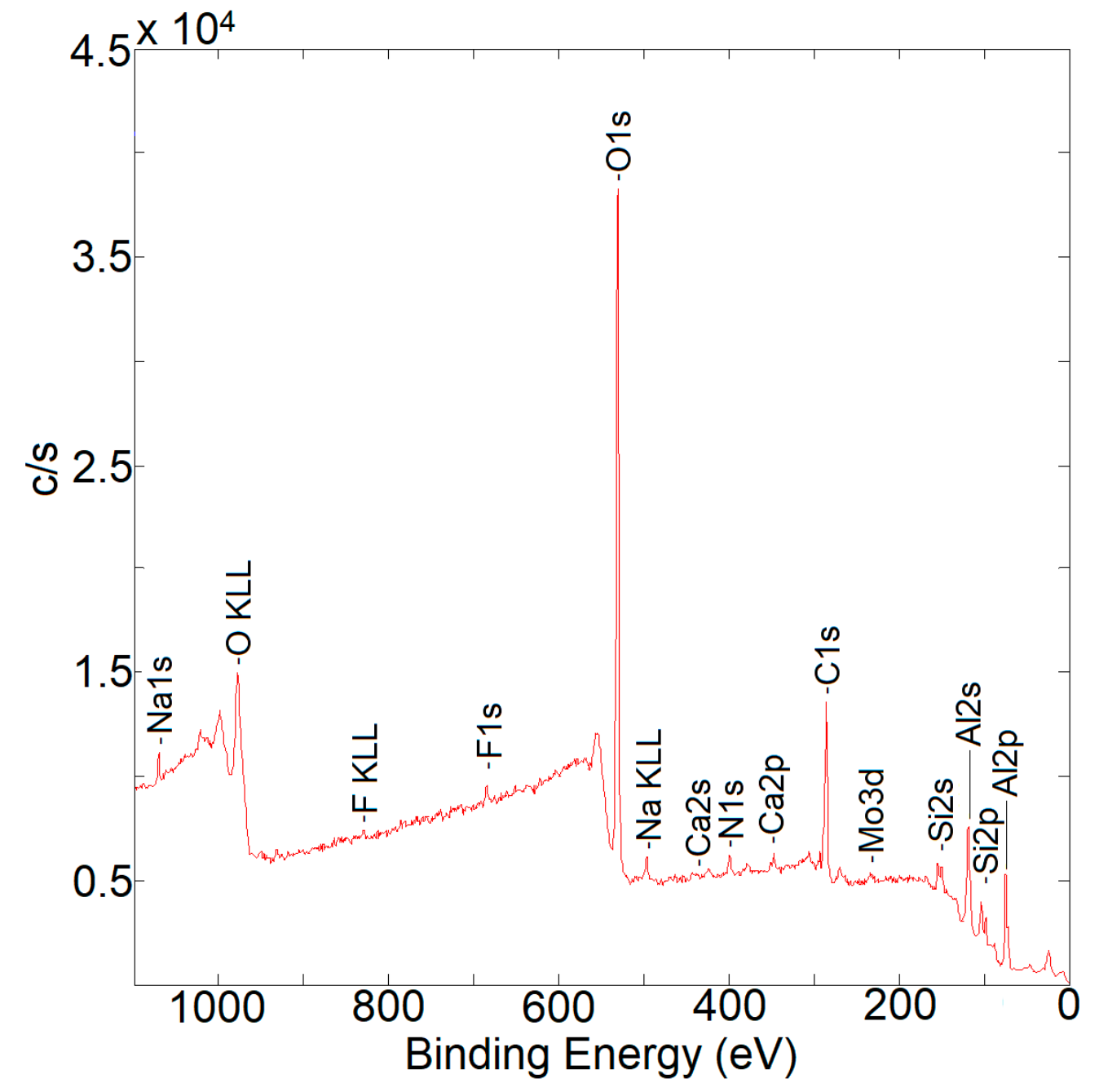

Figure 6. Results of XPS analysis: survey spectrum of the original surface.

Table 2. Microhardness results of the obtained samples.

\begin{tabular}{cc}
\hline Sample Code & Hardness, HV50 \\
\hline 1 & Sample destroyed \\
\hline 2 & $105 \pm 3$ \\
\hline 3 & $110 \pm 3$ \\
\hline 4 & $162 \pm 5$ \\
\hline 5 & $170 \pm 5$ \\
\hline 6 & Sample destroyed \\
\hline 7 & Sample destroyed \\
\hline 8 & $111 \pm 3$ \\
\hline 9 & $138 \pm 4$ \\
\hline 10 & $172 \pm 5$ \\
\hline
\end{tabular}


Table 2. Cont.

\begin{tabular}{cl}
\hline Sample Code & Hardness, HV50 \\
\hline 11 & Sample destroyed \\
\hline 12 & Sample destroyed \\
\hline 13 & Sample destroyed \\
\hline 14 & Sample destroyed \\
\hline 15 & Sample destroyed \\
\hline
\end{tabular}

The results of spectral analysis are shown in Table 3. The presence of oxides explains the presence of residual oxygen in the sample. After 1 min of etching, residual oxygen was detected on the surface of the printed sample. It can be attributed to the presence of $\mathrm{SiO}_{2}$ oxide. The presence of oxygen after $3 \mathrm{~min}$ of etching was attributed to the presence of $\mathrm{Al}_{2} \mathrm{O}_{3}$. During the XPS analysis, ion etching allows analyzing several underlying layers of the material surface. The oxygen concentration reaches its maximum value on the initial surface: it decreases but remains relatively high after etching. This residual oxygen is present in samples due to the presence of $\mathrm{Al}_{2} \mathrm{O}_{3} . \mathrm{SiO}_{2}$ ion etching rate is about $10 \mathrm{~nm} / \mathrm{min}$, an approximate etching rate of $\mathrm{Al}_{2} \mathrm{O}_{3}$ is about $5 \mathrm{~nm} / \mathrm{min}$. The first etching for $1 \mathrm{~min}$ reduced the contribution of the $\mathrm{Al}$ oxide peak from $80 \%$ to $40 \%$. The second etching for 2 min led to a decrease in the contribution from $\mathrm{Al}_{2} \mathrm{O}_{3}$ to $20 \%$. The presence of aluminum and silicon oxides leads to differential charging when recording spectra: binding energy of the oxide spectra turns out to be overestimated due to positive charging during the emission of photoelectrons from layers with low electrical conductivity. The elements $\mathrm{Cu}$, $\mathrm{Mg}$, $\mathrm{Fe}$, and $\mathrm{Mn}$, appeared after the ion etching, i.e., removing adsorbed impurities. After etching, the concentration of metallic aluminum increases. This trend is associated with the surface oxidation of samples due to the high affinity of aluminum to oxygen. Therefore, the composition of the alloying components changes when the oxide film is overcome during the etching process.

Table 3. Elemental composition at printed samples surface.

\begin{tabular}{|c|c|c|c|c|c|c|c|c|c|c|c|c|c|}
\hline \multirow{2}{*}{ Etching Time, $\min$} & \multicolumn{13}{|c|}{ Elemental Composition, at.\%. } \\
\hline & $\mathrm{C}$ & $\mathbf{O}$ & Al & $\mathrm{Si}$ & $\mathrm{Cu}$ & $\mathrm{Mg}$ & $\mathrm{Fe}$ & Mn & $\mathbf{N}$ & $F$ & $\mathrm{Ca}$ & $\mathrm{Na}$ & K \\
\hline- & 25.1 & 42.5 & 19.7 & 8.0 & - & - & - & - & 2.1 & 0.7 & 0.4 & 1.1 & 0.4 \\
\hline 1 & - & 39.0 & 52.0 & 6.4 & 1.2 & 0.7 & 0.3 & 0.4 & - & - & - & - & - \\
\hline 3 & - & 20.6 & 70.0 & 7.7 & 0.7 & 0.4 & 0.3 & 0.3 & - & - & - & - & \\
\hline
\end{tabular}

Obtaining crack-free metal-diamond composite is a challenging task because such material tends to graphitize at relatively high temperatures. As known [22,28], diamond particles tend to graphitize after heating to high temperatures about $1500{ }^{\circ} \mathrm{C}$ in the inert atmosphere and $1000^{\circ} \mathrm{C}$ in the standard atmosphere. Nanodiamond graphitization at atmospheric pressure starts approximately in the temperature range of $670-800{ }^{\circ} \mathrm{C}$ [29]. When synthetic diamond particles are fabricated, metals are used as catalysts and could be present in a diamond as impurities, decreasing the beginning temperature of graphitization. At the same time, low-temperature processing of aluminum in the casting of composite materials makes it possible to exclude diamond graphitization and produce $\mathrm{Al}-\mathrm{C}$ compositions. As we can estimate based on a literature review on SLM parameters [12], the temperature of aluminum processing during laser melting with high power (300-400 W) and high energy input could rise up to $2000{ }^{\circ} \mathrm{C}$, which is significantly higher than nanodiamond graphitization temperature. That is why we can assume $500 \mathrm{~nm}$ diamond graphitization during the SLM process. Besides that, there is also a possibility of laser-induced reaction between carbon and inclusions of absorbed water in aluminum powders, leading to $\mathrm{CO}$ gas release and pore formation during the printing process. 
The influence of the SLM parameters on the material hardness was investigated, and results were presented in Table 2. An increase in LED up to a level of $2.7 \mathrm{~J} / \mathrm{mm}^{2}$ leads to a decrease in microhardness to $105 \pm 3 \mathrm{HV}$ due to the formation of microcracks and defects. The highest hardness values of obtained samples of the Al-C composite $(170 \pm 5 \mathrm{HV})$ is higher than the hardness of the AlSi10Mg material obtained by highpressure die casting (95-105 HV) [30], as well as the hardness of the AlSi10MgCu alloy after SLM (150-155 HV) [31]. Based on the results obtained, it can be assumed that optimal printing parameters of the SLM process of Al-C composite material lie in the area of $1.40-2.0 \mathrm{~J} / \mathrm{mm}^{2}$ energy density or in the area of a lower energy density than that corresponding to the modes indicated in Table 1 . We assume that a lower energy density of less than $1.17 \mathrm{~J} / \mathrm{mm}^{2}$ could prevent the graphitization of nanodiamond particles and lead to better interaction of materials at the matrix/nanodiamond interface, which increases the microhardness of the material and leads to a decrease in the formation of defects.

The results of the XRD analysis are presented in Figure 7. XRD analysis shows the presence of the $\mathrm{Al}_{4} \mathrm{C}_{3}$ phase, the formation of which occurs under the influence of laser radiation to $\mathrm{Al}$-diamond composite powder. In the process of selective laser melting, carbon is partially transformed into carbide and, in addition, there is a possibility of the formation of other modifications of carbon that were not detected by the used methods.

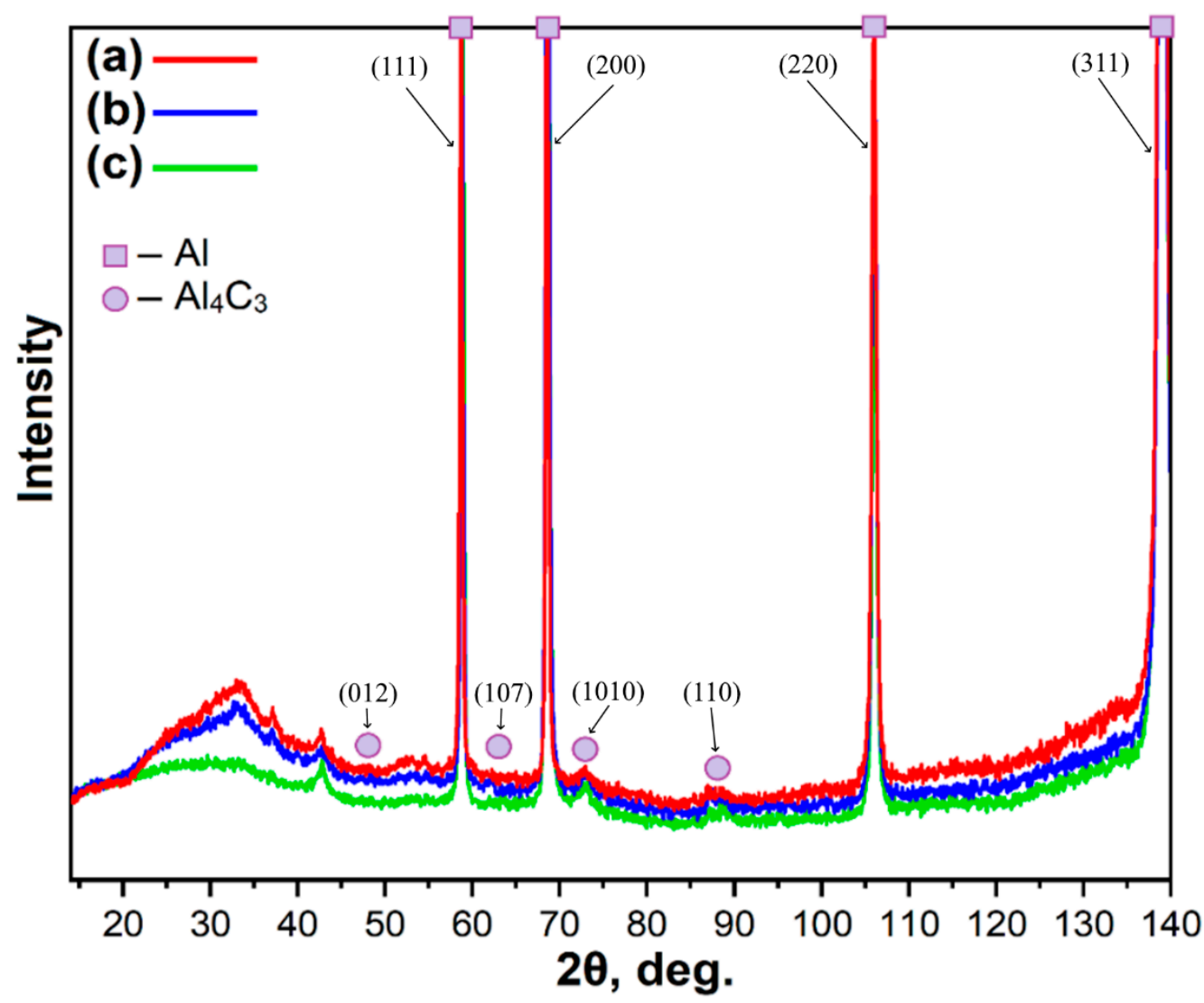

Figure 7. SLM printed Al-C composite samples: $(\mathbf{a}-\mathbf{c})$ lines represent the XRD spectrum of synthesized Al-C samples 2, 4, 8 . 
Besides the influence of the generalized value of laser heat input, the influence of individual parameters also needs to be taken into account. Figure 8 shows the results of optical microscopy of samples synthesized at a laser power of $300 \mathrm{~W}$. As can be seen from the figure, the number of structural defects decreases with increasing scanning speed. Thus, the low scanning speed increases the duration of contact of the laser spot with the processed material, which leads to graphitization of the composite, partial evaporation of the material, and the formation of internal defects.

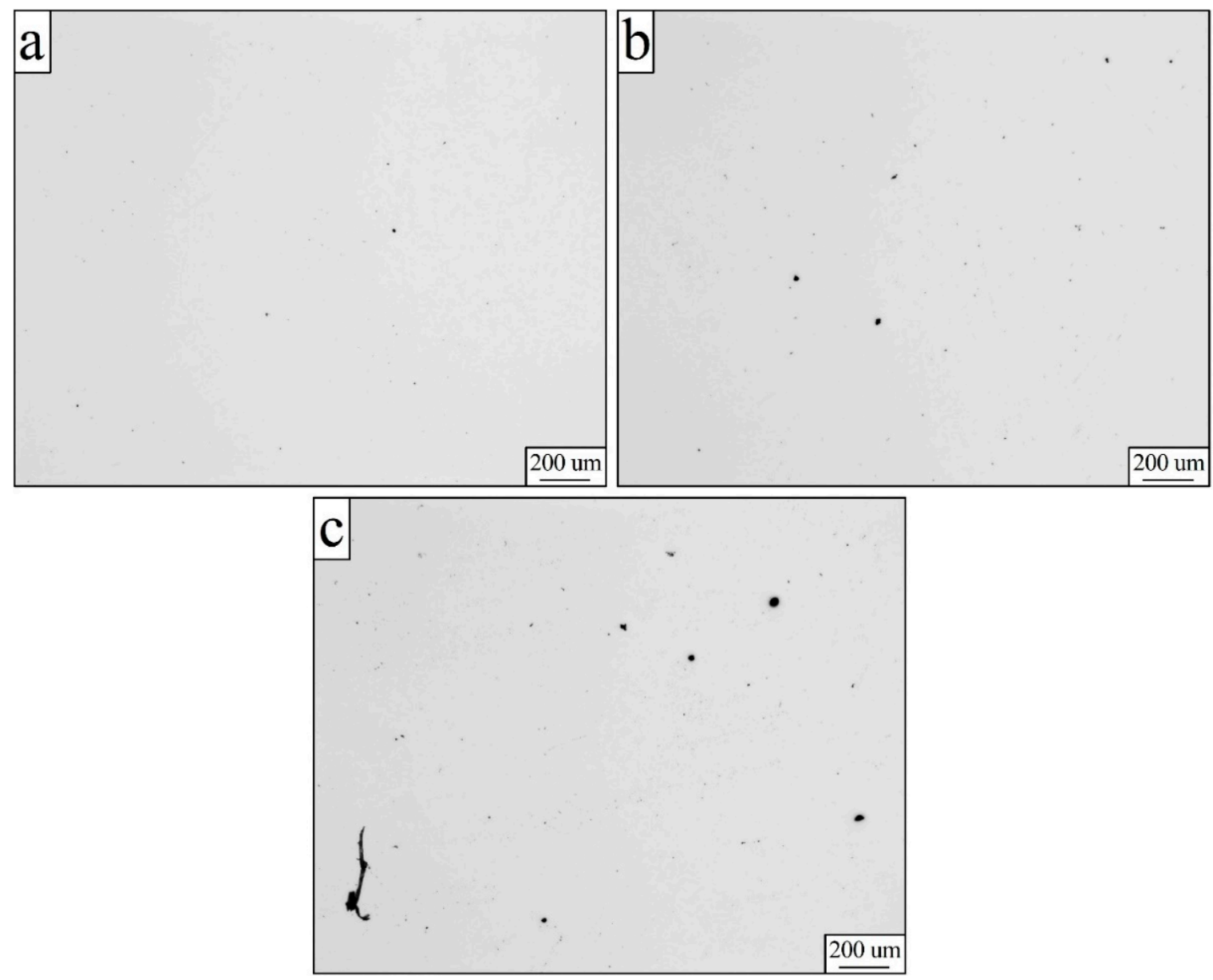

Figure 8. Results of optical microscopy of synthesized samples: (a) sample \#10 ( $\mathrm{P}=300 \mathrm{~W}, \mathrm{~V}=1650 \mathrm{~mm} / \mathrm{s})$; (b) sample \#9 $(\mathrm{P}=300 \mathrm{~W}, \mathrm{~V}=1450 \mathrm{~mm} / \mathrm{s})$; (c) sample \#8 ( $=300 \mathrm{~W}, \mathrm{~V}=1250 \mathrm{~mm} / \mathrm{s})$.

SEM images of the Al-C samples (Figure 9) show the presence of carbon in printed material.

The element map provided gives us an understanding that carbon has probably partly transformed into the aluminum carbide, which is also proved by the XRD analysis results. $\mathrm{Al}_{4} \mathrm{C}_{3}$ carbide is formed during the interaction of an aluminum matrix and graphitized diamond when carbon is introduced into the matrix in an amount exceeding the limit of its solubility in liquid aluminum. 


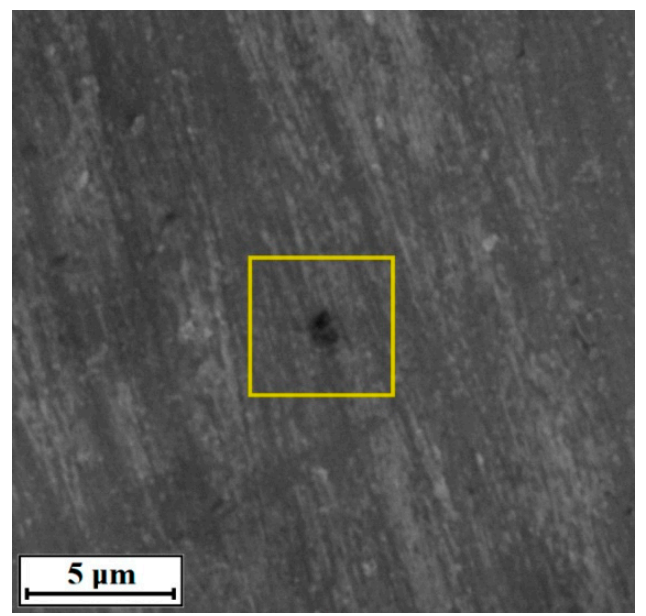

(a)

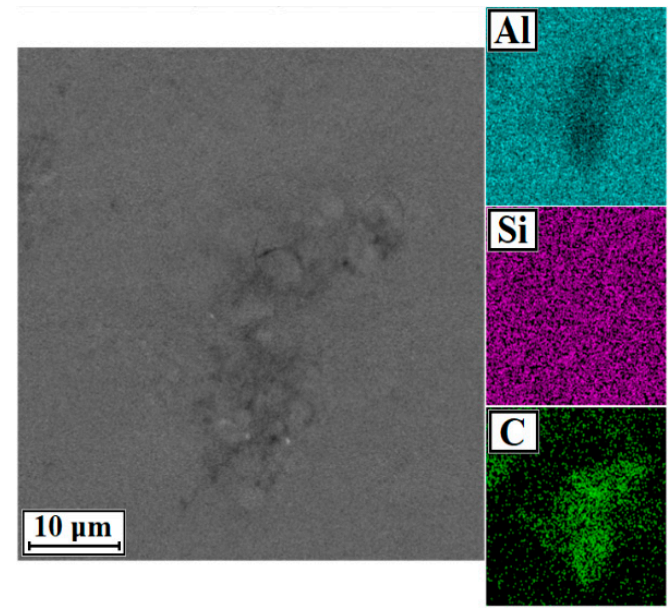

(b)

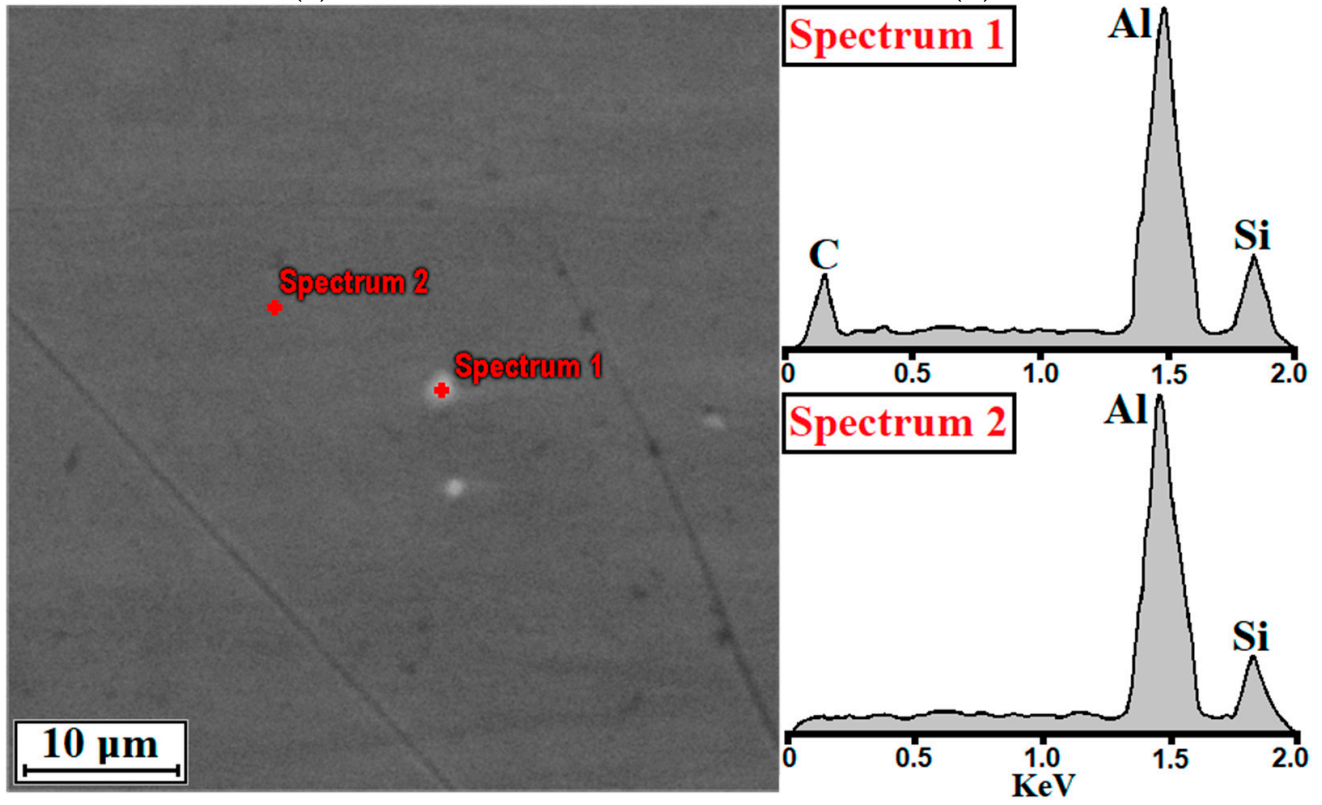

(c)

Figure 9. Characterization of the printed Al-C samples: (a) SEM image; (b) chemical distribution map; (c) EDX analysis.

\section{Conclusions}

Aluminum-matrix composite material was synthesized based on the alloy AlSi10MgCu. The process of obtaining printed samples of a powder composite reinforced with additives of nanodiamond particles was studied, and the presence of carbon in the synthesized composite material obtained by the selective laser melting method was confirmed. The resulting composites are characterized by increased hardness values comparing to the initial AlSi10MgCu material without reinforcing particles.

The highest microhardness values were obtained at the printing regime of $300 \mathrm{~W}$ laser power and $1650 \mathrm{~mm} / \mathrm{s}$ scan speed. Based on the results obtained, it can be assumed that optimal printing parameters of the SLM process of Al-C composite material lie in the area of $1.40-2.0 \mathrm{~J} / \mathrm{mm}^{2}$ energy density along with laser energy exceeding $300 \mathrm{~W}$. Such conditions allow to obtain dense composite material with the carbide phase and increased hardness. At a high power density, an undesirable graphitization process of diamond inclusions may occur; hence proper sintering of the samples is hampered. The principal possibility of obtaining a composite material Al-C with improved properties was shown. 
Author Contributions: Conceptualization, A.S.S. and A.Y.N.; data curation, M.A.B. and S.V.C.; formal analysis, I.A.P., D.Y.O. and A.A.G.; investigation, S.A.E. and V.N.A.; methodology, S.A.E. and V.N.A.; supervision, A.Y.N. and A.A.G.; visualization, A.S.S., S.V.C. and M.A.B.; writing-original draft, A.S.S. and A.Y.N.; writing-review and editing, I.A.P. and D.Y.O. All authors have read and agreed to the published version of the manuscript.

Funding: The preparation of composite powders and the study of the SLM process was financially supported by the Russian Science Foundation (RSF), grant no. 19-79-30025. The study of the nanodiamonds and the detailed characterization of carbon-containing objects was carried out within the framework of the State assignment \# 075-00268-20-02 (ID: 0718-2020-0040).

Institutional Review Board Statement: Not applicable.

Informed Consent Statement: Not applicable.

Data Availability Statement: The data presented in this study are available on request from the corresponding author. The data are not publicly available due to privacy.

Conflicts of Interest: The authors declare no conflict of interest.

\section{References}

1. Torralba, J.; da Costa, C.; Velasco, F. P/M aluminum matrix composites: An overview. J. Mater. Process. Technol. 2003, 133, 203-206. [CrossRef]

2. Sato, A.; Mehrabian, R. Aluminum matrix composites: Fabrication and properties. Metall. Trans. B 1976, 7, 443-451. [CrossRef]

3. Prasad, D.S.; Shoba, C.; Ramanaiah, N. Investigations on mechanical properties of aluminum hybrid composites. J. Mater. Res. Technol. 2014, 3, 79-85. [CrossRef]

4. Zhao, X.; Gu, D.; Ma, C.; Xi, L.; Zhang, H. Microstructure characteristics and its formation mechanism of selective laser melting $\mathrm{SiC}$ reinforced Al-based composites. Vacuum 2019, 160, 189-196. [CrossRef]

5. Wen, X.; Wang, Q.; Mu, Q.; Kang, N.; Sui, S.; Yang, H.; Lin, X.; Huang, W. Laser solid forming additive manufac-turing TiB2 reinforced 2024Al composite: Microstructure and mechanical properties. Mater. Sci. Eng. A 2019, 745, 319-325. [CrossRef]

6. Kimura, T.; Nakamoto, T.; Suyama, T.; Miki, T. In-Process Fabrication of Carbon-Dispersed Aluminum Matrix Composite Using Selective Laser Melting. Metals 2020, 10, 619. [CrossRef]

7. Wang, H.; Gu, D. Nanometric TiC reinforced AlSi10Mg nanocomposites: Powder preparation by high-energy ball milling and consolidation by selective laser melting. J. Compos. Mater. 2015, 49, 1639-1651. [CrossRef]

8. Aversa, A.; Marchese, G.; Saboori, A.; Bassini, E.; Manfredi, D.; Biamino, S.; Ugues, D.; Fino, P.; Lombardi, M. New Aluminum Alloys Specifically Designed for Laser Powder Bed Fusion: A Review. Materials 2019, 12, 1007. [CrossRef]

9. Manfredi, D.; Calignano, F.; Krishnan, M.; Canali, R.; Paola, E.; Biamino, S.; Ugues, D.; Pavese, M.; Fino, P. Additive Manufacturing of Al Alloys and Aluminium Matrix Composites (AMCs). In Light Metal Alloys Applications; InTech: London, UK, 2014.

10. Gu, D.; Chang, F.; Dai, D. Selective Laser Melting Additive Manufacturing of Novel Aluminum Based Composites With Multiple Reinforcing Phases. J. Manuf. Sci. Eng. 2015, 137. [CrossRef]

11. Chen, B.; Xi, X.; Tan, C.; Song, X. Recent progress in laser additive manufacturing of aluminum matrix composites. Curr. Opin. Chem. Eng. 2020, 28, 28-35. [CrossRef]

12. Pelevin, I.A.; Nalivaiko, A.Y.; Ozherelkov, D.Y.; Shinkaryov, A.S.; Chernyshikhin, S.V.; Arnautov, A.N.; Zmanovsky, S.V.; Gromov, A.A. Selective Laser Melting of Al-Based Matrix Composites with Al2O3 Reinforcement: Features and Advantages. Materials 2021, 14, 2648. [CrossRef]

13. Gromov, A.A.; Nalivaiko, A.Y.; Ambaryan, G.N.; Vlaskin, M.S.; Buryakovskaya, O.A.; Kislenko, S.A.; Zhuk, A.Z.; Shkolnikov, E.I.; Slyusarskiy, K.V.; Osipenkova, A.A.; et al. Aluminum-Alumina Composites: Part I: Obtaining and Characterization of Powders. Materials 2019, 12, 3180. [CrossRef]

14. Xi, L.; Guo, S.; Gu, D.; Guo, M.; Lin, K. Microstructure development, tribological property and underlying mecha-nism of laser additive manufactured submicro-TiB2 reinforced Al-based composites. J. Alloys Compd. 2020, 819, 152980. [CrossRef]

15. Ozherelkov, D.Y.; Eremin, S.A.; Anikin, V.N.; Chernyshikhin, S.V.; Nalivaiko, A.Y.; Gromov, A.A. On the mechanism of electrochemical deposition of graphene on Al foils and AlSi10MgCu particles. Mat. Chem. Phys. 2021, 267, 124673. [CrossRef]

16. Zhao, Z.; Bai, P.; Misra, R.D.K.; Dong, M.; Guan, R.; Li, Y.; Zhang, J.; Tan, L.; Gao, J.; Ding, T.; et al. AlSi10Mg alloy nanocomposites reinforced with aluminum-coated graphene: Selective laser melting, interfacial microstructure and property analysis. J. Alloys Compd. 2019, 792, 203-214. [CrossRef]

17. Fang, X.; Yang, Z.; Tan, S.; Duan, L. Feasibility Study of Selective Laser Melting for Metal Matrix Diamond Tools. Crystals 2020, 10, 596. [CrossRef]

18. Gan, J.; Gao, H.; Wen, S.; Zhou, Y.; Tan, S.; Duan, L. Simulation, forming process and mechanical property of Cu-Sn-Ti/diamond composites fabricated by selective laser melting. Int. J. Refract. Met. Hard Mater. 2020, 87, 105144. [CrossRef]

19. Sundqvist, B. Carbon under pressure. Phys. Rep. 2021, 909, 1-73. [CrossRef] 
20. Liang, X.; Jia, C.; Chu, K.; Chen, H.; Nie, J.; Gao, W. Thermal conductivity and microstructure of Al/diamond com-posites with Ti-coated diamond particles consolidated by spark plasma sintering. J. Compos. Mater. 2012, 46, 1127-1136. [CrossRef]

21. Ma, Y.; Ji, G.; Li, X.P.; Chen, C.Y.; Tan, Z.Q.; Addad, A.; Li, Z.Q.; Sercombe, T.B.; Kruth, J.P. On the study of tailorable interface structure in a diamond/Al12Si composite processed by selective laser melting. Materialia 2019, 5. [CrossRef]

22. Spierings, A.B.; Leinenbach, C.; Kenel, C.; Wegener, K. Processing of metal-diamond-composites using selective laser melting. Rapid Prototyp. J. 2015, 21, 130-136. [CrossRef]

23. Constantin, L.; Kraiem, N.; Wu, Z.; Cui, B.; Battaglia, J.L.; Garnier, C.; Silvain, J.F.; Lu, Y.F. Manufacturing of com-plex diamondbased composite structures via laser powder-bed fusion. Addit. Manuf. 2021, 40, 101927. [CrossRef]

24. Sherif El-Eskandarany, M. Mechanical solid state mixing for synthesizing of SiCp/Al nanocomposites. J. Alloys Compd. 1998, 279, 263-271. [CrossRef]

25. Liao, J.; Tan, M.-J. Mixing of carbon nanotubes (CNTs) and aluminum powder for powder metallurgy use. Powder Technol. 2011, 208, 42-48. [CrossRef]

26. Sergienko, A.V.; Solovieva, K.N.; Balakhnina, A.V.; Petrov, E.A.; Ozherelkov, D.Y.; Nalivaiko, A.Y.; Gromov, A.A. Nanodiamonds characterization and application as a burning rate modifier for solid propellants. Mater. Today Commun. 2021, $27,102332$. [CrossRef]

27. Jang, D.M.; Im, H.S.; Back, S.H.; Park, K.; Lim, Y.R.; Jung, C.S.; Park, J.; Lee, M. Laser-induced graphitization of colloidal nanodiamonds for excellent oxygen reduction reaction. Phys. Chem. Chem. Phys. 2014, 16, 2411-2416. [CrossRef] [PubMed]

28. Rabinkin, A.; Shapiro, A.E.; Boretius, M. Brazing of diamonds and cubic boron nitride. In Advances in Brazing; Woodhead Publishing: Sawston, UK, 2013; pp. 160-193. [CrossRef]

29. Rahman, A.; Frangeskou, A.; Kim, M. Burning and graphitization of optically levitated nanodiamonds in vacuum. Sci. Rep. 2016, 6, 21633. [CrossRef]

30. Kempen, K.; Thijs, L.; Van Humbeeck, J.; Kruth, J.P. Mechanical properties of AlSi10Mg produced by selective laser melting. Phys. Procedia 2012, 39, 439-446. [CrossRef]

31. Martin, A.; San Sebastian, M.; Gil, E.; Wang, C.Y.; Milenkovic, S.; Pérez-Prado, M.T.; Cepeda-Jiménez, C.M. Effect of the heat treatment on the microstructure and hardness evolution of a AlSi10MgCu alloy designed for laser powder bed fusion. Mater. Sci. Eng. A 2021, 141487. [CrossRef] 